\title{
An NMR crystallographic approach to monitoring cation substitution in the aluminophosphate STA-2
}

\author{
Valerie R. Seymour, Eike C. V. Eschenroeder, Paul A. Wright \\ and Sharon E. Ashbrook*
}
School of Chemistry, EaStCHEM and Centre of Magnetic Resonance, University of St Andrews, North Haugh, St Andrews KY16 9ST, UK

*Author to whom correspondence should be addressed.

E-mail: sema@st-andrews.ac.uk 


\section{Abstract}

The substitution of the divalent cations $\mathrm{Mg}^{2+}$ and $\mathrm{Zn}^{2+}$ into the aluminophosphate (AlPO) framework of STA-2 has been studied using an "NMR crystallographic" approach, combining multinuclear solid-state NMR spectroscopy, X-ray diffraction and firstprinciples calculations. Although the AlPO framework itself is inherently neutral, the positive charge of the organocation template in an as-made material is usually balanced either by the coordination to the framework of anions from the synthesis solution, such as $\mathrm{OH}^{-}$or $\mathrm{F}^{-}$, and/or by the substitution of aliovalent cations. However, the exact position and distribution of the substituted cations can be difficult to determine, but can have a significant impact upon the catalytic properties a material exhibits once calcined.

For as-made Mg substituted STA-2, the positive charge of the organocation template is balanced by the substitution of $\mathrm{Mg}^{2+}$ for $\mathrm{Al}^{3+}$ and, where required, by hydroxide anions coordinated to the framework. ${ }^{27} \mathrm{Al}$ MAS NMR spectra show that $\mathrm{Al}$ is present in both tetrahedral and five-fold coordination, with the latter dependent on the amount of substituted cations, and confirms the bridging nature of the hydroxyl groups, while high-resolution MQMAS spectra are able to show that Mg appears to preferentially substitute on the Al1 site. This conclusion is also supported by first-principles calculations. The calculations also show that $31 \mathrm{P}$ chemical shifts depend not only on the topologicallydistinct site in the SAT framework, but also on the number of next-nearest-neighbour $\mathrm{Mg}$ species, and the exact nature of the coordinated hydroxyls (whether the $\mathrm{P}$ atom forms part of a six-membered ring, $\mathrm{P}(\mathrm{OAl})_{2} \mathrm{OH}$, where $\mathrm{OH}$ bridges between two $\mathrm{Al}$ atoms). The calculations demonstrate a strong correlation between the ${ }^{31} \mathrm{P}$ isotropic chemical shift and the average $<\mathrm{P}-\mathrm{O}-\mathrm{M}>$ bond angle. In contrast, for Zn substituted STA-2, both X-ray diffraction and NMR spectroscopy show less preference for substitution onto Al1 or A12, with both appearing to be present, although that into Al1 appears slightly more favoured.

Keywords: NMR crystallography, Solid-state MAS NMR, Aluminophosphates, Firstprinciples calculations, Cation substitution and disorder 


\section{Introduction}

Aluminophosphates (AlPOs), first reported in the $1980 \mathrm{~s}^{1}{ }^{1}$ are a widely studied group of zeotypes, with a range of industrial and medical applications. ${ }^{2-3}$ The synthesis of an AlPO typically requires a structure-directing agent (SDA), sometimes referred to as the "template", such as an organic amine base, in order to favour open framework formation over a dense phase. ${ }^{2-3}$ The tetrahedrally-connected $\mathrm{AlPO}_{4}$ framework is inherently neutral, but because the SDA is usually positively charged, a charge-balancing mechanism is required for "as-made" materials. This can be achieved in pure AlPOs by the coordination of anions from the synthesis solution, such as $\mathrm{OH}^{-}$or $\mathrm{F}^{-}$, to the aluminium cations of the framework. ${ }^{2-3}$ The SDA, the charge-balancing anions and any water present can usually be removed by calcination to produce the neutral "empty" framework. However, charge balance can also be achieved by substituting suitable cations into the framework, and aluminophosphate-based zeotypes with a range of additional metals in framework sites, such as magnesium, manganese, iron, cobalt and zinc, have also been prepared.3,4 Indeed many AlPO-based zeotypes have only been crystallised in the "MAPO" form including, for example, DAF-1 and STA-1.4-6 Removal of the template from these materials gives porous solids with catalytic properties, either as solid Lewis or Bronsted acids or, if metals that exhibit redox properties (e.g., Mn, Fe or Co) are present, as oxidation catalysts.3,4

The STA-2 zeotype was first reported in 1997,6,7 and was prepared in a MgAPO (i.e., $\mathrm{Mg}$ containing) form, using bis-quinuclidinium-butane (BQNB) as the SDA. The BQNB template has a 2+ charge and a charge-balancing mechanism is required in the as-made templated materials. In principle, this can be achieved inherently, by the substitution of $\mathrm{Mg}^{2+}$ ions for $\mathrm{Al}^{3+}$ ions in the framework. However, for samples with a low amount of $\mathrm{Mg}$, anions (usually hydroxide for STA-2) are also required to ensure sufficient charge balance. In most STA-2 materials, therefore, two charge-balancing mechanisms are possible, and in many cases, operate simultaneously. The incorporation of $\mathrm{Mg}$ into a MgAPO framework may occur in a random, (partial) ordered, or preferential fashion.3,4 In the initial characterisation of MgAPO STA-2 (by diffraction) it was stated that "no effort was made 
to locate the magnesium, which is expected on the basis of experience to substitute randomly for aluminium in the structure".6,7 The pure AlPO form of STA-2 was synthesized subsequently, using both BQNB and bis-diazabicyclooctanebutane (BDAB) as SDAs, and characterised using a combination of X-ray diffraction and solid-state NMR spectroscopy. 8,9

The structure of STA-2 (framework type SAT) can be described in terms of the stacking of its secondary building units (SBUs), where six-membered rings (6MRs) are stacked at different positions in the xy plane of a hexagonal unit cell, and are connected via four-membered rings (4MRs). Consequently, the framework contains single and double six-membered rings (S6Rs and D6Rs, respectively), 4MRs and both cancrinite (CAN) and elongated cages, as shown in Figure $1 a \cdot{ }^{6-9}$ In the calcined framework there are two topologically-distinct cation sites (occupied by Al only in the pure AlPO), and two topologically-distinct P sites, with A12 and P1 located in D6R units, and Al1 and P2 located in S6R units. These units join to form the CAN cages, which share a $4 \mathrm{MR}$ face. Consequently, Al1 is bonded, via oxygen, to one P1 and three P2, and Al2 is bonded, via oxygen, to one P2 and three P1. In as-made materials, the divalent template occupies the elongated cages (see Figure 1b) and, as there are three of these in the full unit cell (i.e., $\mathrm{Al}_{36} \mathrm{P}_{36} \mathrm{O}_{144}$ ), this requires the introduction of six negative charges to compensate. In the pure AlPO form, this was previously shown to be achieved by the introduction of six hydroxyl groups, occupying the CAN cages.8,9 For the MgAPO form synthesised initially, charge balance can occur both by $\mathrm{OH}^{-}$incorporation and by $\mathrm{Mg}^{2+}$ substitution. A fully Mg-substituted AlPO (i.e., where no hydroxyl groups are required) would have a $\mathrm{Mg} / \mathrm{P}$ ratio of 1/6. $\mathrm{Mg}$ cations could potentially substitute (either in an ordered or random manner) on to one $\mathrm{Al}$ tetrahedral site (exclusively or preferentially), or on to both sites equally.

Although a pure AlPO framework exhibits a periodic, repeating structure, the substitution of other elements into this framework, and the potentially disordered arrangement of charge-balancing anions and SDAs, can pose a challenge for diffraction- 
based methods. In particular, standard X-ray diffraction methods are unable to distinguish between isoelectronic $\mathrm{Al}^{3+}$ and $\mathrm{Mg}^{2+}$ cations. Therefore, a more complete and detailed picture, with information on both long-range and local structure, can be obtained by combining high-resolution NMR spectroscopy and conventional crystallographic diffraction. Aluminophosphate-based frameworks are well suited to investigation by NMR spectroscopy, as the basic components of the framework $\left({ }^{27} \mathrm{Al},{ }^{31} \mathrm{P}\right.$ and $\left.{ }^{17} \mathrm{O}\right)$ can be studied, and NMR-active species are also present in the SDA $\left(e . g .,{ }^{13} \mathrm{C},{ }^{1} \mathrm{H}\right.$ and $\left.{ }^{15} \mathrm{~N}\right)$ and the charge-balancing anions (e.g., ${ }^{17} \mathrm{O},{ }^{1} \mathrm{H}$ and $\left.{ }^{19} \mathrm{~F}\right)$. Although it is the combination of diffraction and NMR spectroscopy that is often termed "NMR crystallography", in many cases additional insight can be gained by using first-principles calculations to bridge between these two techniques, recently referred to as "SMARTER crystallography". 10 The advances in computation for periodic systems in recent years (most notably, in the context of the calculation of NMR parameters, with the advent of the GIPAW approach ${ }^{11}$ ) has resulted in a step change in the number and breadth of applications of these methods in NMR spectroscopic investigations. ${ }^{12}$ For phosphate frameworks, calculations have been used primarily to facilitate spectral assignment and to identify the phase(s) present and their interconversion. $8,9,13$ However, the real power of such calculations lies in their ability to aid interpretation of the complicated spectral lineshapes that are observed for disordered materials, providing detailed insight into the atomic-scale structure.

In this work, we combine diffraction, NMR spectroscopy and calculations to investigate in detail the charge-balancing mechanisms operating in MgAPO STA-2. We consider a series of materials with varying amounts of $\mathrm{Mg}$ in an attempt to assess whether any preferential siting of the Mg occurs. In addition, we compare our findings to similar STA-2 materials prepared in the presence of $\mathrm{Zn}^{2+}$ precursors.

\section{Experimental Details}

\section{Synthesis and Characterisation}


The substituted forms of STA-2 studied in this work were prepared in an analogous way to the method published previously in Ref. 7. In a typical synthesis the gel composition given in Table 1 was used. The metal sources were magnesium or zinc acetate. Before use in the AlPO synthesis the hydroxyl form of the BQNB template was prepared by hydroxide ion exchange of the bromide form over the hydroxide form of the Amberlite ${ }^{\circledR}$ IRN78 resin. In each case the maximum targeted level of substitution of $\mathrm{M}^{2+}$ (for $\mathrm{Al}^{3+}$ ) was $1 / 6$, which should enable full charge balance of the positive template to be achieved. The crystallisation was carried out in Teflon-lined static autoclaves at $190{ }^{\circ} \mathrm{C}$ for 6 to 7 days. The resulting product was purified by sonication, filtered and dried at $60{ }^{\circ} \mathrm{C}$ overnight.

Samples were analysed by powder X-ray diffraction (PXRD) (using a PANalytic Empyrean diffractometer) and EDX analysis (using a JEOL JSM-5600 SEM equipped with an Oxford INCA Energy200 EDX analyser). The M/P ratios for the samples produced are given in Table 2, and are the average of at least seven individual EDX measurements. For more detail see the Supplementary Information.

\section{NMR Spectroscopy}

NMR spectra were acquired using Bruker Avance III spectrometers operating at $\mathrm{B}_{0}$ field strengths of $14.1 \mathrm{~T}\left({ }^{27} \mathrm{Al},{ }^{31} \mathrm{P}\right.$ and $\left.{ }^{25} \mathrm{Mg}\right)$ or $9.4 \mathrm{~T}\left({ }^{1} \mathrm{H}\right)$, at Larmor frequencies of 156.4 $\mathrm{MHz}\left({ }^{27} \mathrm{Al}\right), 242.9 \mathrm{MHz}\left({ }^{31} \mathrm{P}\right), 36.7 \mathrm{MHz}\left({ }^{25} \mathrm{Mg}\right)$ and $400.13\left({ }^{1} \mathrm{H}\right)$. Powdered samples were packed into conventional 1.9 or $4 \mathrm{~mm}$ rotors and rotated at MAS rates of $40 \mathrm{kHz}(1.9 \mathrm{~mm})$ and between 10 and $14 \mathrm{kHz}(4 \mathrm{~mm})$. Typical recycle intervals were $1 \mathrm{~s}\left({ }^{27} \mathrm{Al}\right), 60 \mathrm{~s}\left({ }^{31} \mathrm{P}\right), 1 \mathrm{~s}$ $\left({ }^{25} \mathrm{Mg}\right)$ and $5 \mathrm{~s}\left({ }^{1} \mathrm{H}\right)$. Chemical shifts are reported (in ppm) relative to $1 \mathrm{M} \mathrm{Al}\left(\mathrm{NO}_{3}\right)_{3}(\mathrm{aq})$, $85 \% \mathrm{H}_{3} \mathrm{PO}_{4}(\mathrm{aq}), 1 \mathrm{M} \mathrm{MgSO}_{4}(\mathrm{aq})$ and $\mathrm{TMS}$, for ${ }^{27} \mathrm{Al},{ }^{31} \mathrm{P},{ }^{25} \mathrm{Mg}$ and ${ }^{1} \mathrm{H}$, respectively. For ${ }^{27} \mathrm{Al}$ and ${ }^{31} \mathrm{P}$ conventional MAS spectra were acquired, while for ${ }^{1} \mathrm{H}$ a spin-echo was employed. For ${ }^{25} \mathrm{Mg}$, spectra were acquired using a Carr-Purcell-Meiboom-Gill (CPMG) ${ }^{14}$ pulse sequence to improve sensitivity. 80 echoes were acquired with a spacing of $2.4 \mathrm{~ms}$, giving a spikelet spacing of $416 \mathrm{~Hz}$ in the Fourier-transformed spectrum. For ${ }^{27} \mathrm{Al}$, triple- 
quantum MAS NMR experiments were carried out using a phase-modulated split- $\mathrm{t}_{1}$ shifted-echo pulse sequence, ${ }^{15}$ with the final pulse chosen to be selective for the central transition. The scale in the indirect dimension was referenced according to the convention in Ref. 16.

\section{DFT calculations}

First-principles density functional theory (DFT) calculations were performed for a reduced unit cell of STA-2 (of formula $\left.\mathrm{Al}_{12} \mathrm{P}_{12} \mathrm{O}_{48}(\mathrm{BQNB})(\mathrm{OH})_{2}\right)$, as shown Figure 1c, with varying $\mathrm{Mg}$ locations within the framework. The $\mathrm{Mg} / \mathrm{P}$ ratio was chosen to be 0.167 , so full charge balance could be achieved purely by cation substitution, without any additional hydroxyls. The initial structure used was based on the dehydrated STA2(BDAB) structure (obtained from diffraction measurements in previous work ${ }^{7,9}$ ) with the SDA manually changed from BDAB to BQNB (i.e., replacement of the apical $\mathrm{N}$ with $\mathrm{CH}$ ), to match that used in the experimental work presented here, all hydroxyls removed and two framework Al replaced with $\mathrm{Mg}$ (to satisfy the charge). Calculations were carried out using the CASTEP DFT code (version 5.5.2),17 employing the GIPAW algorithm, 11 to reconstruct the all-electron wavefunction in the presence of a magnetic field. Calculations were performed using the GGA PBE functional, ${ }^{18}$ with core-valence interactions described by ultrasoft pseudopotentials. ${ }^{19}$ The dispersion correction scheme of Tkatchenko and Scheffler (TS) was used.20 A planewave energy cutoff of 50 Ry was used, and integrals over the Brillouin zone were performed using a Monkhorst-Pack grid with k-point spacing of $0.04 \AA^{-1}$. Calculations were performed on a 198-node (2376 core) Intel Westmere cluster with 2-4 GB memory per core and QDR Infiniband interconnect at the University of St Andrews. Prior to the calculation of NMR parameters, geometry optimisation was performed with the positions of all atoms, and the unit cell size and shape, allowed to vary. Previous work has discussed the utility of semi-empirical dispersion correction schemes for structural optimisation of phosphate-based frameworks. ${ }^{21}$ Typical calculation times for the optimisations were 2 to 8 days, after which

the forces on the atoms had reduced to typically much less than $1 \mathrm{eV}^{-1}$, although the 
optimization was not "converged" (within the criteria specified: $1 \times 10^{-4} \mathrm{eV}$ per atom, 0.05 $\mathrm{eV} \AA^{-1}$ and $1 \times 10^{-3} \AA$ for total energy, ionic force and ionic displacement, respectively), at this point. This may well be due to motion of the template within the pores, rather than any change in the position of the framework atoms. A subset of structures was further optimised to an energy minimum (taking a total of up to an additional 9 days for each optimisation), after which the forces on the atoms had reduced to less than $0.05 \mathrm{eV} \AA^{-1}$.

Calculations generate the absolute shielding tensor $(\sigma)$ and the electric field gradient (EFG) tensor $(V)$ in the crystal frame. In each case, diagonalisation yields the three principal components of the tensor $\left(\sigma_{X X}, \sigma_{Y Y}\right.$ and $\sigma_{Z Z}$ for the shielding tensor and $V_{X X}$, $V_{Y Y}$ and $V_{Z Z}$ for the EFG tensor). The isotropic shielding, $\sigma_{\text {iso }}=(1 / 3) \operatorname{Tr}\{\sigma\}$, and the isotropic chemical shift, $\delta_{\text {iso, }}$ is given by $-\left(\sigma_{\text {iso }}-\sigma_{\text {ref }}\right)$, where $\sigma_{\text {ref }}$ is a reference shielding. This was determined to be 550.41 ppm for ${ }^{27} \mathrm{Al}$ and 278.81 ppm for ${ }^{31} \mathrm{P}$, from calculations carried out on calcined AlPO STA-2. The magnitude of the quadrupolar coupling constant is given by $C_{Q}=e Q V_{z Z} / h$, where $Q$ is the nuclear quadrupole moment (for which a value of $146.6 \mathrm{mB}$ was used for $\left.{ }^{27} \mathrm{Al}\right) .{ }^{22}$ The asymmetry parameter is given by $\eta_{\mathrm{Q}}=\left(\mathrm{V}_{\mathrm{XX}}-\right.$ $\left.\mathrm{V}_{\mathrm{YY}}\right) / \mathrm{V}_{\mathrm{ZZ}}$.

\section{Results and Discussion}

MgAPO STA-2

Owing to the size of the crystals it was not possible to carry out single-crystal diffraction experiments, and PXRD experiments were performed (see Figure S1.1 in the Supplementary Information). These indicate that MgAPO STA-2 forms over the compositional range examined (i.e., up to $\mathrm{Mg} / \mathrm{P}$ ratios of 0.17 ). There is some evidence of minor amounts of a second (unidentified) crystalline phase present in samples with $\mathrm{Mg} / \mathrm{P}$ ratios of 0.06 and 0.07 , but samples at the higher ratios $(0.16,0.17)$ are phase pure by PXRD. 
In the ${ }^{27} \mathrm{Al}$ MAS NMR spectrum of as-made pure AlPO STA-2 reported previously, 8,9 and shown also in Figure 2a, two distinct sets of resonances are observed, with those between 35 and 50 ppm corresponding to four-coordinate $\mathrm{Al}\left(\mathrm{Al}^{\mathrm{IV}}\right)$ and those between 0 and $20 \mathrm{ppm}$ to five-coordinate $\mathrm{Al}\left(\mathrm{Al}^{\mathrm{V}}\right)$ (due to the coordinated hydroxyl groups). Two hydroxyls are required to charge balance each SDA molecule and these were shown in previous work (using an NMR crystallographic approach) to reside in the CAN cages, strictly one per cage, bridging two different framework $\mathrm{Al}$ species, i.e., $\mathrm{Al1-O}(\mathrm{H})$ Al2. ${ }^{9}$ In the as-made material, therefore, the presence of the hydroxyls and template will result in variation of the local environment of the two topologically-distinct Al sites identified for the calcined material. As in previous work, here we adopt the following nomenclature to describe the different sites: the six Al located in S6Rs (i.e., formally Al1 in the calcined material) ${ }^{8,9}$ are now denoted Al11-Al16, whereas those in D6Rs (i.e., formally A12 in the calcined material) are denoted A121-A126. Similarly P11-P16 and P21-P26 refer to P sites derived from P1 (D6R) and P2 (S6R), respectively, in the calcined material. ${ }^{8}$

In previous work, DFT calculations were used to assign the ${ }^{27} \mathrm{Al}$ MAS NMR spectra of the pure AlPO form of STA-2. ${ }^{9}$ These were carried out on a series of models where hydroxyls were located on two of six possible sites identified by diffraction within the CAN cages. However, BDAB was used as the template molecule (rather than the BQNB used here). It was also shown by the same authors 8,9 that the NMR spectra of AlPO STA-2 materials synthesised using the two different templates were almost identical - hence the conclusions from previous work can be extended to apply to materials produced using BQNB. In the $\mathrm{Al}^{\mathrm{IV}}$ region of the spectrum the signal at higher shift can be assigned to Al21Al26 (i.e., that in D6R), that at lower shift to Al11-Al16 (i.e., that in S6R), while resonances from Al11-Al16 and Al21-Al26 (now with hydroxyls attached) overlap in the $\mathrm{Al}^{\mathrm{V}}$ region of the spectrum. It was shown that the two $\mathrm{Al}^{\mathrm{IV}}$ resonances can be resolved in a twodimensional triple-quantum MAS spectrum, but that the $\mathrm{Al}^{\mathrm{V}}$ resonances remain overlapped. 
The ${ }^{27} \mathrm{Al}$ MAS NMR spectra of as-made MgAPO STA-2(BQNB) materials are also shown in Figure 2a, with the corresponding triple-quantum MAS spectra shown in Figure S2.1 of the Supplementary Information. Average NMR parameters extracted from these spectra are given (along with values for the pure AlPO form) in Table 3. At low levels of $\mathrm{Mg}$ substitution the spectrum is (as expected) very similar to the pure AlPO form. All materials exhibit significant signal intensity between 30 and 50 ppm, corresponding to Al ${ }^{\mathrm{IV}}$ species. For samples with $\mathrm{Mg} / \mathrm{P}$ ratios of 0.03 and 0.04 , significant signal intensity is also observed in the $\mathrm{Al}^{\mathrm{V}}$ region of the spectrum (between 0 and $20 \mathrm{ppm}$ ), due to the coordination of the bridging hydroxyl groups (still required for charge balance). This signal decreases significantly in intensity as the $\mathrm{Mg} / \mathrm{P}$ ratio approaches $1 / 6$. In principle, at this point, charge balance of the template can be achieved solely by cation substitution into the framework, and no hydroxyls are required, producing a purely tetrahedral ( $\left.\mathrm{Al}^{\mathrm{IV}}\right)$ framework. There are, however, small amounts of higher-coordinated Al still present in many of the spectra, albeit contributing only a small percentage of the total intensity. This could arise either from a discrepancy in the reported quantity of $\mathrm{Mg}$ included in the framework (i.e., a small number of hydroxyls are still required to maintain charge balance), the presence of $\mathrm{H}_{2} \mathrm{O}$ coordinating to the framework $\mathrm{Al}$ or from a small amount of impurity phase. In this context, it should be noted that minor impurities have been observed in the ${ }^{27} \mathrm{Al}$ MAS NMR spectrum of pure AlPO STA-2 in previous work. 8,9 Although small amounts of water are thought to be present in the pure AlPO form, this was shown not to be coordinated to the framework $\mathrm{Al}$ (as the ${ }^{27} \mathrm{Al}$ and ${ }^{31} \mathrm{P} \mathrm{NMR}$ spectra did not change upon dehydration, although some intensity was lost from the ${ }^{1} \mathrm{H}$ MAS spectrum). ${ }^{8,9}$ It is possible for MgAPO STA-2 that the loss of coordinating hydroxyls results in a small amount of coordinated water molecules, particularly for samples with higher $\mathrm{Mg} / \mathrm{P}$ ratios. The coordination of water has been postulated by other authors to explain low levels of more highly-coordinated Al in other MgAPO phases.,23-24 Although complicated by potential overlap of signals from $\mathrm{OH}^{-}$and $\mathrm{H}_{2} \mathrm{O}$, the ${ }^{1} \mathrm{H}$ MAS NMR spectra (shown in Figure 2c) confirm the variation in charge-balancing mechanism with composition, showing a decrease in the intensity of the peak at $\sim 5$ ppm (and so loss of $\left.\mathrm{OH}^{-}\right)$as the $\mathrm{Mg} / \mathrm{P}$ ratio increases. 
As described previously, the ratio of the intensities of signals from $\mathrm{Al}^{\mathrm{IV}}$ and $\mathrm{Al}^{\mathrm{V}}$ species provides information on the bonding mode (i.e., terminal or bridging) of incorporated hydroxyls. For pure AlPO STA-2, $\mathrm{Al}^{\mathrm{V}}$ : $\mathrm{Al}^{\mathrm{IV}}$ would be $1: 5$ if the hydroxyls are terminal, and $1: 2$ if they are bridging between $\mathrm{Al}$ species). The relative intensities of the Al species in the MAS spectra of MgAPO STA-2 samples are given in Table 4. Neglecting the low intensity $\mathrm{Al}{ }^{\mathrm{VI}}$ species, the $\mathrm{Al}^{\mathrm{V}} / \mathrm{Al}^{\mathrm{IV}}$ ratio is much closer to that expected for bridging rather than terminal hydroxyls for each sample (taking into account the loss of $\mathrm{Al}$ from the cell), demonstrating that the bonding mode of the hydroxyl groups does not appear to vary when additional charge balance is also achieved with cation substitution. The agreement with predicted intensities is not as good as with the pure AlPO form, but this is not unexpected when the increased disorder, the uncertainties in the exact composition, the possibility of a small amount of coordinated water molecules and the possible presence of minor impurity phases are considered.

Although $\mathrm{Al}^{\mathrm{V}}$ resonances resulting from Al11-Al16 and Al21-Al26 cannot be resolved in triple-quantum MAS NMR spectra of AlPO STA-2, it is possible to resolve sites in the $\mathrm{Al}^{\mathrm{IV}}$ region of the spectrum.8,9 Two major resonances can be resolved in this region, with a third minor resonance appearing as a partially resolved shoulder. Similar spectra are observed for the MgAPO STA-2 materials, although (presumably as a result of the increased disorder present), the shoulder is not typically resolved. The (average) NMR parameters extracted (Table 3) are in broad agreement with those of the AlPO form, although small variations are observed owing to the presence of overlapping sites. The NMR parameters, however, change very little with composition, suggesting that the local $\mathrm{Al}$ environment is very similar, even at the highest levels $(\mathrm{Mg} / \mathrm{P}=0.17)$ of $\mathrm{Mg}$ substitution. For pure AlPO STA-2, the two major AlV resonances could be identified as resulting from Al11-Al16 $\left(\delta_{1} \approx 22 \mathrm{ppm}\right)$ and Al21-A26 ( $\left.\delta_{1} \approx 26 \mathrm{ppm}\right)$, using DFT calculations, and were present in the spectrum in approximately a $1: 1$ ratio (as the hydroxyls bridge between Al1 and Al2 species). Although MQMAS is not quantitative, the two resonances exhibit similar average $C_{Q}$ values, and the variation in their relative 
intensities can be considered with reasonable accuracy. Assuming that the assignment above holds for the MgAPO samples (this is clearly a reasonable assumption at low $\mathrm{Mg}$ content, and its validity will be discussed in more detail below for samples with higher $\mathrm{Mg}$ content), Table 5 shows that the ratio of the intensities of resonances resulting from AlIV species from Al11-Al16 ( $\left.\delta_{1} \approx 22 \mathrm{ppm}\right)$ and Al21-A26 $\left(\delta_{1} \approx 26 \mathrm{ppm}\right)$, extracted from the MQMAS spectra of MgAPO STA-2, appears generally to decrease as the Mg content increases. If the $\mathrm{Mg}$ were randomly distributed between the two types of $\mathrm{Al}$ sites, it would be expected that they would remain in approximately a $1: 1$ ratio in the spectrum. However, at higher Mg contents very little signal results from four-coordinate Al11-Al16, indicating that there appears a preferential substitution of $\mathrm{Mg}$ onto sites derived from Al1 (i.e., into the S6R rather than the D6R). This can clearly be seen in Figure 3, where the isotropic projections of the ${ }^{27} \mathrm{Al}$ MQMAS spectra of $\mathrm{MgAPO}$ STA-2 with $\mathrm{Mg} / \mathrm{P}$ ratios of 0.03 and 0.17 are compared. There is a clear decrease in the intensity of the resonance at lower $\delta_{\square}$, resulting from Al in S6R (i.e., Al1). Preferential substitution of divalent cations has previously been observed in AlPO structures, where it has been attributed to different local geometries for different $\mathrm{Al}$ sites, ${ }^{25}$ but relatively little difference in geometry is observed for Al1 and Al2 species in as-made STA-2.

The ${ }^{31} \mathrm{P}$ MAS NMR spectrum of as-made AlPO STA-2 (reported previously ${ }^{8,9}$ ) is also shown for comparison in Figure 2b. Three intense resonances are observed, between 20 and -40 ppm. DFT calculations carried out previously for a range of models of AlPO STA-2 with varying positions of the hydroxyls, were able to assign the three main resonances. ${ }^{9}$ The resonance at -27 ppm was shown to result from P in D6R (i.e., P11-P16), while the two less intense resonances, at -23 and -33 ppm, result from P in S6R (i.e., P21P26). The difference in chemical shift is observed when any neighbouring $\mathrm{Al}^{\mathrm{V}}$ species in the $\mathrm{P}(\mathrm{OAl})_{4}$ tetrahedra are coordinated to the same hydroxyl group, i.e., whether the two Al species the hydroxyl group bridges are attached to the same $\mathrm{P}$ atom. If this is the case, this produces a significant decrease in the average P-O-Al bond angle, and a corresponding increase in the chemical shift. ${ }^{26}$ 
The ${ }^{31} \mathrm{P}$ MAS NMR spectra of MgAPO STA-2 materials are shown in Figure 2b. All materials show overlapping peaks in the region -10 to $-40 \mathrm{ppm}$, corresponding, as expected, to $\mathrm{PO}_{4}$ environments. A similar amorphous impurity to that seen in pure AlPO STA-2 is also observed at higher shift for samples with lower Mg doping. At low levels of Mg substitution the spectra look similar to that of the pure AlPO STA-2, as the incorporation of hydroxyls remains the major charge-balancing mechanism, and can be assigned in a similar manner. The spectra become increasingly complex as the $\mathrm{Mg}$ substitution level increases, with the appearance of a number of additional resonances, reflecting the presence of two significant charge-balancing mechanisms. The resonance at -27 ppm, ascribed previously to "P1" $(\mathrm{OAl})_{4}$, appears to remains throughout the series of materials, as does that at -33 ppm, which results from "P2" $(\mathrm{OAl})_{4}$, although this does decrease in intensity as the $\mathrm{Mg} / \mathrm{P}$ ratio increases. The peak at higher shift, ascribed to $\mathrm{P}$ in S6R (i.e., P21-P26) with neighbouring $\mathrm{Al}^{\mathrm{V}}$ species coordinated to the same hydroxyl group, broadens and decreases in intensity as the $\mathrm{Mg} / \mathrm{P}$ ratio increases and hydroxyls are removed from the material, confirming its suggested assignment.

It is known from the literature that the ${ }^{31 P}$ chemical shift is affected both by the local geometry (e.g., $\mathrm{P}-\mathrm{O}-\mathrm{Al}$ bond angles in a $\mathrm{P}(\mathrm{OAl})_{4}$ tetrahedron $)^{26}$ and also by the nature of the atoms on the next nearest neighbor (NNN) sites, i.e., $\mathrm{Al}$ in AlPOs. The substitution of other elements for $\mathrm{Al}$, such $\mathrm{Mg}$, Co or $\mathrm{Zn}$, has been shown to have a pronounced effect on the ${ }^{31} \mathrm{P}$ chemical shift in AlPO-based materials. ${ }^{24,27}$ For MgAPO materials, the shift has been shown to increase with the substitution of $\mathrm{Mg}$, i.e., with $\mathrm{P}(\mathrm{OAl})_{4}$ having a more negative shift than $\mathrm{P}(\mathrm{OAl})_{3}(\mathrm{OMg})$, etc., and the ${ }^{31} \mathrm{P}$ spectra of a number of MgAPOs, such as MgAPO-11 and MgAPO-36, have been assigned in this way. ${ }^{24}$ Such a simple analysis is complicated for STA-2, not only because two formally topologically-distinct species are present, but also by the presence of hydroxyl groups (i.e., two charge balancing mechanisms in some of the samples) and the additional changes in ${ }^{31} \mathrm{P}$ shift that these produce. Consequently, simple deconvolution of the spectral lineshapes is not possible without further information. 
Although it might be expected that ${ }^{25} \mathrm{Mg}$ NMR spectroscopy could provide the most direct information on the substitution of $\mathrm{Mg}$ in AlPOs, and the atomic-scale environment it experiences, the low $\gamma$, low sensitivity, 10\% natural abundance and large quadrupolar broadening limits the ease of application of this technique. A ${ }^{25} \mathrm{Mg}$ CPMG MAS NMR spectrum of MgAPO STA-2 (with $\mathrm{Mg} / \mathrm{P}=0.07$ ) is shown in the Supplementary Information, and confirms that $\mathrm{Mg}$ has been successfully incorporated into the framework. The presence of quadrupolar broadening (and, perhaps more importantly, the distribution of NMR parameters expected) prevents any more detailed conclusions at this stage, although the position and width of the resonance is consistent with the presence of tetrahedral $\mathrm{Mg}$.

DFT calculations were also carried out to gain further insight into Mg substitution into AlPO STA-2. In previous work, the STA-2 structures considered were of the formula $\mathrm{Al}_{12} \mathrm{P}_{12} \mathrm{O}_{48}(\mathrm{BDAB})(\mathrm{OH})_{2}$, with different arrangements of the hydroxyls. As described above these calculations remain useful when considering the ${ }^{27} \mathrm{Al}$ and ${ }^{31} \mathrm{P}$ spectrum of $\mathrm{MgAPOs}$ with low Mg doping. To consider the spectra obtained for samples with higher $\mathrm{Mg} / \mathrm{P}$ ratios, a second set of DFT calculations were carried out, starting from the unit cell shown in Figure 1c, containing $\mathrm{Al}_{10} \mathrm{Mg}_{2} \mathrm{P}_{12} \mathrm{O}_{48}(\mathrm{BQNB})$, i.e., a $\mathrm{Mg} / \mathrm{P}$ ratio of $1 / 6$. At this composition, charge balance can be obtained purely through cation substitution and no hydroxyl groups are required. Structures with varying positions of Mg substitution were considered, with models divided into three sets; (i) those with Mg substituted only onto Al1, (ii) those with Mg substituted only onto Al2 and (iii) those with Mg substituted onto both Al1 and Al2. Further details are given in the Supplementary Information.

Figure 4 shows the ranges of ${ }^{27} \mathrm{Al}$ and ${ }^{31} \mathrm{P}$ calculated isotropic chemical shifts, $\delta_{\text {iso, }}$ for each of the three sets of substituted model compounds. (Only data for fully optimised models are shown here, but more detailed information on a greater range of partially optimised models is given in the Supplementary Information). The range of ${ }^{27} \mathrm{Al}$ chemical shifts observed in each set of models is similar to that found for the pure AlPO (i.e., with charge balancing by hydroxyls) and confirms the assignment of the two broadened 
resonances as Al in D6Rs (i.e., Al21-26) at higher shift and S6R Al (i.e., Al11-Al16) at lower shift. Therefore, the site for preferential $\mathrm{Mg}$ substitution in the sample with $\mathrm{Mg} / \mathrm{P}=0.17$ discussed above can also be confirmed as Al1, i.e., S6R sites. Very similar shift ranges are predicted for each of the three possible types of substitution, suggesting that ${ }^{27} \mathrm{Al}$ MAS spectra will not be able to distinguish between them. For each set of models, it is also possible to consider the relative positions of the two substituted $\mathrm{Mg}$ cations. These can share SBUs, e.g., the same CAN cage, $6 \mathrm{MR}$, D6R or $4 \mathrm{MR}$, or the two can be found in a combination of these. The Supplementary Information shows that calculated ${ }^{27} \mathrm{Al}$ chemical shifts are very similar for all relative positions of the two $\mathrm{Mg}$ cations, indicating that this remote substitution (i.e., $\mathrm{Al}-\mathrm{O}-\mathrm{P}-\mathrm{O}-\mathrm{M}$ ) has little effect on the local $\mathrm{AlO}_{4}$ environment.

As shown in Figure 4, the range of calculated ${ }^{31} \mathrm{P}$ isotropic chemical shifts encompasses that obtained experimentally. For each $\mathrm{P}$ species it can be seen that there is a systematic change of the average ${ }^{31} \mathrm{P} \delta_{\text {iso }}$ as $\mathrm{Mg}$ is substituted, with an increase in shift as the number of $\mathrm{Mg}$ NNN cations increases, as suggested in previous literature. ${ }^{26}$ The change in average shift (and distribution of shifts) observed appears slightly larger for P2 (in the S6R) than for P1 (in D6R), suggesting these resonances may appear more spaced and somewhat broader in the spectrum. However, in general, the ranges predicted for P1 and P2 species will significantly overlap in the spectrum, making unambiguous and accurate spectral deconvolution difficult. It is possible to identify the resonance at the lowest shift as resulting exclusively from "P2" (4 Al, $0 \mathrm{Mg}$ ), i.e., P21-P26 sites with no Mg NNN, but more difficult to unambiguously assign the overlapped resonances.

Although the ranges of shifts calculated for the three different sets of models are quite similar, it is worth remembering that P species in S6R (i.e., P2) have 3 Al1 species and $1 \mathrm{Al} 2$ as NNN, and so are relatively more likely to have $\mathrm{Mg} \mathrm{NNN}$ if $\mathrm{Mg}$ substitutes preferentially onto Al1, as discussed above. This would match with the decrease in intensity observed for the resonance at the lowest chemical shift, "P2" (4 Al, $0 \mathrm{Mg})$. In contrast, if $\mathrm{Mg}$ substituted preferentially onto $\mathrm{Al} 2$, this resonance would be predicted to have a relatively much greater intensity. Whilst certainly not unambiguous by any means, 
the ${ }^{31} \mathrm{P}$ DFT calculations are certainly consistent with the proposal of preferential substitution of $\mathrm{Mg}$ onto Al1.

Figure 5 shows the calculated ${ }^{31} \mathrm{P}$ isotropic chemical shifts, now plotted as a function of the average $<\mathrm{P}-\mathrm{O}-\mathrm{M}>$ (where $\mathrm{M}$ is $\mathrm{Al}$ or $\mathrm{Mg}$ ), bond angle. There is a clear trend, with a decrease in chemical shift resulting from an increase in the average $<\mathrm{P}-\mathrm{O}-\mathrm{M}>$ angle. Although a good correlation is clear when all data are considered, when sites with different Mg NNN are distinguished, it can be seen that there are three stronger positive correlations present. The overall spread of $<\mathrm{P}-\mathrm{O}-\mathrm{M}>$ angles for P1 (in the D6R) is generally smaller than that for $\mathrm{P} 2$, resulting in the smaller range of calculated shifts.

From the DFT calculations it is also possible to consider the predicted ${ }^{25} \mathrm{Mg} \mathrm{NMR}$ parameters when $2 \mathrm{Mg}$ substitute onto Al1, Al2 or both Al1 and Al2 simultaneously. As shown in the Supplementary Information, the distribution of chemical shifts and quadrupolar couplings observed are very similar for $\mathrm{Mg}$ in a D6R or a S6R site, and are not able to distinguish between the three different models. In general, the calculated parameters are in good agreement with the experimental spectrum, but no additional, more detailed, information can be obtained.

The DFT calculations carried out provide insight into the appearance of the spectral lineshapes and, in some cases, have enabled assignment of some of the resonances. For ${ }^{31} \mathrm{P}$, they demonstrate the validity of the assumption in previous work that increasing the number of Mg NNN does indeed result in an increase in the ${ }^{31} \mathrm{P}$ chemical shift, and also demonstrate the effect upon this shift of a variation in the $<\mathrm{P}-\mathrm{O}-\mathrm{M}>$ bond angle. However, although a number of resonances can be distinguished in the ${ }^{31} \mathrm{P}$ MAS NMR spectra, DFT calculations show that these result from the overlap of signals from different species. This of course, is even more of a problem for MgAPO samples with $\mathrm{Mg} / \mathrm{P}<0.167$, where two different charge-balancing mechanisms are present simultaneously, and both have a significant effect upon the chemical shift. For zeotypes with more than one topologically- 
distinct site, it is clear that any deconvolution must be approached with significant caution.

ZnAPO STA-2

For comparison, STA-2 samples prepared with $\mathrm{Zn}^{2+}$ substitution were also investigated. PXRD shows that for ZnAPO compositions with Zn/P ratios up to 0.07, STA2 is the only crystalline phase, with minor impurities present for samples with higher substitution levels - see the Supplementary Information for more detail. For the sample with $\mathrm{Zn} / \mathrm{P}$ of $0.07, \mathrm{XRD}$ refinement confirmed that $\mathrm{Zn}^{2+}$ substituted for $\mathrm{Al}^{3+}$, with substitution observed for both Al1 and Al2 sites, although a preference for Al1 substitution was suggested. However, it should be noted that not all of the $\mathrm{Zn}$ in the sample (based on the EDX measurement) could be located in the refinement.

The ${ }^{27} \mathrm{Al},{ }^{31} \mathrm{P}$ and ${ }^{1} \mathrm{H}$ MAS NMR spectra of ZnAPO STA-2 are shown in Figure 6. As observed for MgAPO STA-2, there is a gradual decrease in the amount of $\mathrm{Al}^{\mathrm{V}}$ species present in the spectrum as the $\mathrm{Zn}$ content increases, confirming that $\mathrm{Zn}^{2+}$ is substituting into the framework, and fewer hydroxyls are needed to charge balance. This is also confirmed by the ${ }^{1} \mathrm{H}$ MAS spectra, which show loss of intensity of the signal at $~ 5$ ppm, attributed to the hydroxyls. The $\mathrm{Al}^{\mathrm{V}}$ signal does not completely disappear, however, as the $\mathrm{Zn} / \mathrm{P}$ ratio is never $1 / 6$ (as significant impurity phases were formed at higher $\mathrm{Zn}$ substitution levels). There appear to be no $\mathrm{Al}^{\mathrm{VI}}$ species present, suggesting that (unlike the MgAPO samples) little water is incorporated into the emptying pores, or that different impurity phases are present. As observed for the MgAPO and pure AlPO phases, the ${ }^{27} \mathrm{Al}$ (and ${ }^{31} \mathrm{P}$ ) NMR spectra reveal the presence of an amorphous impurity (not observed by diffraction) at low $\mathrm{Zn} / \mathrm{P}$ ratios.

The ${ }^{27} \mathrm{Al}$ MQMAS spectra of the ZnAPO phases are given in the Supplementary Information, and parameters extracted from these given in Table 3. At low Zn content, these look similar to those for the pure AlPO and low Mg content MgAPO, with two major 
resonances resolved in the $\mathrm{Al}^{\mathrm{IV}}$ region of the spectrum, but only a broad resonance seen in the $\mathrm{Al}^{\mathrm{V}}$ region. Furthermore, the NMR parameters are very similar (both within the $\mathrm{ZnAPO}$ series and between the MAPO materials, again suggesting that the remote substitution (i.e., of Al-O-P-O-M) has little effect upon the local Al environment. By analogy, the $\mathrm{Al}{ }^{\mathrm{IV}}$ resonance at higher ppm in $\delta_{1}$ can be attributed to Al2 (D6R) species, and that at lower shift to Al1 (S6R). The ratio of the (integrated) intensities of the $\mathrm{Al}^{\mathrm{IV}}$ resonances resulting from Al1 (Al11-Al16) and Al2 (A121-26) are given in Table 5. This appears to drop slightly from the $1: 1$ observed for the pure AlPO phase, suggesting some preferential substitution onto Al1, but this is not as apparent as that observed in Figure 3 for the MgAPO phases (although it should be noted that samples with high $\mathrm{Zn} / \mathrm{P}$ ratios, where this effect would be most noticeable, were not able to be prepared). Whilst not definitive, the suggestion of some substitution of Zn onto both Al1 and Al2 sites, but with some preference for Al1 substitution, is in good agreement with the PXRD measurements.

The ${ }^{31} \mathrm{P}$ spectra of ZnAPO STA-2 in Figure 6 are similar to those for the pure AlPO form at low $\mathrm{Zn} / \mathrm{P}$, but the changes observed with composition confirm that $\mathrm{Zn}$ does indeed substitute into the framework. By analogy to the MgAPO described above, the appearance of additional resonances reflects the substitution of $\mathrm{Zn}$ into the NNN environment. ${ }^{27}$ As above, an increase in chemical shift is observed as $\mathrm{Zn}$ is added, but the magnitude of the change appears to be greater than that seen for $\mathrm{Mg}$. The width of the resonances is similar to that observed for the MgAPO phases, indicating that a similar distribution of average $<\mathrm{P}-\mathrm{O}-\mathrm{M}>$ bond angles is present. However, once again, owing to the presence of two P sites, and the overlap of the resulting resonances (particularly as two charge balancing mechanisms are operating simultaneously for all samples and the presence of hydroxyls also results in further resonances), it is not possible to obtain an unambiguous deconvolution of the spectral lineshapes. We hope this is possible in the future, with a combination of DFT calculations and more complex two-dimensional hetero- and homo-nuclear correlation experiments.

\section{Conclusions}


We have shown that the substitution of the divalent cations $\mathrm{Mg}^{2+}$ and $\mathrm{Zn}^{2+}$ into AlPO STA-2 (prepared with a BQNB template) is possible. For $\mathrm{Mg}^{2+}$ we were able to prepare a series of samples up to a $\mathrm{Mg} / \mathrm{P}$ ratio of 0.17 , while for $\mathrm{Zn}^{2+}$ samples were prepared only up to a $\mathrm{Zn} / \mathrm{P}$ ratio of 0.11 , as significant impurity phases were observed with higher $\mathrm{Zn} / \mathrm{P}$ ratios. NMR spectroscopy was shown to be a useful probe of the local structure and cation disorder, and its combination with PXRD and first-principles DFT calculations, in an "NMR crystallographic" approach is the ideal methodology for understanding these materials. DFT calculations on pure AlPO STA-2(BDAB) were used to understand the spectra for the AlPO STA-2(BQNB). The spectra are very similar, with two major $\mathrm{Al}^{\mathrm{IV}}$ resonances observed, with the $1: 1$ ratio indicating that hydroxyls bridge between $\mathrm{Al} 1$ and $\mathrm{Al} 2$ and occupy the cancrinite cages. The increase in the $\mathrm{Al}{ }^{\mathrm{IV}} / \mathrm{Al}^{\mathrm{V}}$ ratio reflects the loss of hydroxyls from the material as more $\mathrm{Mg}$ is substituted, and a change in the charge-balancing mechanism. This observation is also mirrored in the ${ }^{1} \mathrm{H}$ MAS spectrum, where a loss of intensity in the signal attributed to $\mathrm{OH}^{-}$was observed. The $\mathrm{Al}^{\mathrm{IV}} / \mathrm{Al}^{\mathrm{V}}$ ratios observed for $\mathrm{MgAPO} \mathrm{STA}-2$ are more consistent with the remaining hydroxyls occupying bridging rather than terminal sites. The ratio of the two signals in the $\mathrm{Al}^{\mathrm{IV}}$ region of the MQMAS spectrum also varied as $\mathrm{Mg}$ was substituted, and while not truly quantitative, the general trend indicated that $\mathrm{Mg}$ substituted preferentially onto the "Al1" site, i.e., $\mathrm{Al}$ in the S6R rather than in the D6R.

Although a full deconvolution of the ${ }^{31} \mathrm{P}$ NMR spectra was not possible, the presence of additional resonances confirms that $\mathrm{Mg}^{2+}$ is substituting into the framework. DFT calculations showed an increase in chemical shift should be observed as a $\mathrm{Mg}^{2+}$ cation is substituted into the NNN environment, and revealed that the magnitude of the shift was predicted to be slightly larger for P2 (in the S6R) than for P1 (in D6R), suggesting these resonances may appear both more widely spaced and somewhat broader in the spectrum. The line broadening observed was shown to be due to a variation in the average $<\mathrm{P}-\mathrm{O}-\mathrm{M}>$ angle, with a strong correlation between average angle and ${ }^{31} \mathrm{P}$ isotropic chemical shift shown. Although it was not possible to obtain information on the detailed 
substitution and ordering from the spectra, when the relative intensity of the resonances was considered, the data can be seen to be more consistent with preferential substitution onto Al1 not A12, although substitution onto both sites cannot be ruled out.

In contrast, for $\mathrm{ZnAPOs}$ samples with $\mathrm{Zn} / \mathrm{P}$ ratios above 0.11 were not produced and so two charge-balancing mechanisms are expected for each material. Changes in the intensity of the $\mathrm{Al}^{\mathrm{V}}$ resonance, the decrease in the signal attributed at $\mathrm{OH}^{-}$in the ${ }^{1} \mathrm{H}$ spectrum and the presence of additional resonances in the ${ }^{31} \mathrm{P}$ spectrum all confirm the substitution of $\mathrm{Zn}$ into the framework, and the subsequent loss of hydroxyl groups. The ratio of the two signals in the $\mathrm{Al}^{\mathrm{IV}}$ region of the MQMAS spectrum also varied as Zn was substituted, although the lack of samples with higher $\mathrm{Zn} / \mathrm{P}$ ratios results in less unambiguous conclusions. However, the relative ratios suggest that $\mathrm{Zn}$ substitutes onto both Al1 and Al2 sites, but with some preference for Al1. This is also in agreement with the conclusions from the Rietveld refinement of the PXRD data (although it should be noted that not all of the $\mathrm{Zn}$ was able to be located in this analysis). Changes are also observed in the ${ }^{31} \mathrm{P}$ MAS spectra, with the appearance of additional resonances attributed (by analogy to MgAPO STA-2) to the substitution of Zn into NNN sites. The change in shift appears to be slightly greater than that for $\mathrm{Mg}$.

NMR spectroscopy has been able to provide insight into the local structure and order in MgAPO and ZnAPO STA-2 materials, and the associated use of DFT calculations aids interpretation and understanding of the spectra obtained. It may be possible to gain more detailed information (particularly for ZnAPOs) for samples with the higher M/P ratios, through the implementation of more complex two-dimensional correlations experiments for as-made materials and also by considering materials after calcination. In general the combined use of diffraction, NMR and calculations enables a detailed picture of a material on different lengthscales and timescales to be obtained, and offers exciting possibilities for future research.

\section{Acknowledgements}


We would like to thank the Leverhulme Trust (F/00 268/BJ), EPSRC (EP/E041825/1, EP/J501542/1, and EP/F018096/1) and the European Commission FP6 Marie Curie Research Training Network “INDENS" (MRTN-CT-2004-005503) for support. We thank EaStCHEM for computational support through the EaStCHEM Research Computing Facility. Mr Scott Sneddon is thanked for help in the preparation of this manuscript. 


\section{References}

1. S. T. Wilson, B. M. Lok, C. A. Messina, T. R. Cannan and E. M. Flanigen, J. Am. Chem. Soc., 1982, 104, 1146, DOI: 10.1021/ja00368a062.

2. J. Yu and R. Xu, Chem. Soc. Rev., 2006, 35, 593, DOI: 10.1039/B505856M.

3. P. A. Wright, Microporous Framework Solids, RSC Publishing, Cambridge, 2008, DOI: $10.1039 / 9781847557971$.

4. J. Li, J. Yu and R. Xu, Proc. R. Soc. A, 2012, 468, 1955, DOI: 10.1098/rspa.2012.0058.

5. P. A. Wright, R. H. Jones, S. Natarajan, R. G. Bell, J. S. Chen, M. B. Hursthouse and J. M. Thomas, Chem. Commun., 1993, 633, DOI: 10.1039/c39930000633.

6. G. W. Noble, P. A. Wright, P. Lightfoot, R. E. Morris, K. J. Hudson, A. Kvick, H. Graafsma, Angew. Chem. Int. Ed. Engl., 1997, 36, 81, DOI: 10.1002/anie.199700811.7.

7. G. W. Noble, P. A. Wright and A. Kvick, J. Chem. Soc., Dalton Trans., 1997, 4485, DOI: 10.1039/a705091g.

8. M. Castro, V. R. Seymour, D. Carnevale, J. M. Griffin, S. E. Ashbrook, P. A. Wright, D. C. Apperley, J. E. Parker, S. P. Thompson, A. Fecant and N. Bats, J. Phys. Chem., 2010, 114, 12698, DOI: 10.1021/jp104120y.

9. V. R. Seymour, E. C. V. Eschenroeder, M. Castro, P. A. Wright and S. E. Ashbrook, Cryst. Eng. Comm., 2013, 15, 8668, DOI: 10.1039/c3ce40965a.

10. C. Martineau, A. Cadiau, B. Bouchevreau, J. Senker, F. Taulelle and K. Adil, Dalton Trans., 2012, 41, 6232, DOI: 10.1039/C2DT30100H.

11. C. J. Pickard and F. Mauri, Phys. Rev. B: Condens. Matter Mater. Phys., 2001, 63, 245101, DOI: 10.1103/PhysRevB.63.245101.

12. (a) T. Charpentier, Solid State Nucl. Magn. Reson., 2011, 40, 1, DOI: 10.1016/j.ssnmr.2011.04.006; (b) J. Cuny, S. Messaoudi, V. Alonzo, E. Furet, J.-F. Halet, E. Le Fur, S. E. Ashbrook, C. J. Pickard, R. Gautier and L. Le Polles, J. Comput. Chem., 2008, 29, 2279, DOI: 10.1002/jcc.21028; (c) C. Bonhomme, C. Gervais, F. Babonneau, C. Coelho, F. Pourpoint, T. Azais, S. E. Ashbrook, J. M. Griffin, J. R. Yates, F. Mauri and C. J. Pickard, Chem. Rev., 2012, 112, 5733, DOI: 10.1021/cr300108a; (d) S. E. Ashbrook and D. M. Dawson, Acc. Chem. Res., 2013, 46, 1964, DOI: 10.1021/ar300303w. 
13. (a) S. E. Ashbrook, M. Cutajar, J. M. Griffin, Z. A. D. Lethbridge, R. I. Walton and S. Wimperis, J. Phys. Chem. C, 2009, 113, 10780, DOI: 10.1021/jp902074s; (b) S. E. Ashbrook, M. Cutajar, C. J. Pickard, R. I. Walton and S. Wimperis, Phys. Chem. Chem. Phys., 2008, 10, 5754, DOI: 10.1039/b805681a; (c) Z. Han, A. L. Picone, A. M. Z. Slawin, V. R. Seymour, S. E. Ashbrook, W. Zhou, S. P. Thompson, J. E. Parker and P. A. Wright, Chem. Mater., 2010, 22, 338, DOI: 10.1021/cm902528y; (d) P. J. Byrne, J. E. Warren, R. E. Morris and S. E. Ashbrook, Solid State Sci., 2009, 11, 1001, 10.1016/j.solidstatesciences.2009.02.002; (e) M. Amri, S. E. Ashbrook, D. M. Dawson, J. M. Griffin, R. I Walton and S. Wimperis, J. Phys. Chem. C, 2012, 116, 15048, DOI: 10.1021/jp304868w; (f) J. M. Griffin, L. Clark, V. R. Seymour, D. W. Aldous, D. M. Dawson, D. Iuga, R. E. Morris and S. E Ashbrook, Chem. Sci., 2012, 3, 2293, DOI: 10.1039/c2sc20155k.

14. S. Meiboom and D. Gill, Rev. Sci. Instrum., 1958, 29, 688, DOI: 10.1063/1.1716296.

15. S. P. Brown and S. Wimperis, J. Magn. Reson., 1997, 128, 42, DOI: 10.1006/jmre.1997.121.

16. K. J. Pike, R. Malde, S. E. Ashbrook, J. McManus and S. Wimperis, Solid State Nucl. Magn. Reson., 2000, 16, 203, DOI: 10.1016/S0926-2040(00)00081-3.

17. M. D. Segall, P. J. D. Lindan, M. J. Probert, C. J. Pickard, P. J. Hasnip, S. J. Clark and M. C. J. Payne, J. Phys.: Condens. Matter, 2002, 14, 2717, DOI: 10.1088/0953-8984/14/11/301.

18. J. P. Perdew, K. Burke and M. Ernzerhof, Phys. Rev. Lett., 1996, 77, 3865, DOI: 10.1103/PhysRevLett.77.3865.

19. J. R. Yates, C. J. Pickard and F. Mauri, Phys. Rev. B: Condens. Matter Mater. Phys., 2007, 76, 024401, DOI: 10.1103/PhysRevB.76.024401.

20. A. Tkatchenko and M. Scheffler, Phys. Rev. Lett., 2009, 102, 073005, DOI: 10.1103/PhysRevLett.102.073005.

21. S. Sneddon, D. M. Dawson, C. J. Pickard and S. E. Ashbrook, Phys. Chem. Chem. Phys., 2014, 16, 2660, DOI: 10.1039/c3cp54123a.

22. P. Pyykko, Mol. Phys., 2008, 106, 1965, DOI: 10.1080/00268970802018367.

23. F. Deng, Y. Yue, T. C. Xiao, Y. Du, C. Ye, L. An and H. Wang, J. Phys. Chem., 1995, 99, 6029, DOI: 10.1021/j100016a045. 
24. B. Akolekar and R. F. Howe, J. Chem. Soc., Faraday Trans., 1997, 93, 3263, DOI: 10.1039/a701287j.

25. L. Shao, Y. Li, J. Yu and R. Xu, Inorg. Chem. 2012, 51, 225, DOI: 10.1021/ic201515z.

26. (a) D. Muller, E. Jahn, G. Ladwig and U. Haubenreisser, Chem. Phys. Lett., 1984, 109, 332, DOI: 10.1016/0009-2614(84)85596-7; (b) C. S. Blackwell and R. L. Patton, J. Phys. Chem., 1984, 88, 6135, DOI: 10.1021/j150669a016.

27. (a) A. B. Pinar, L. Gomez-Hortiguela, L. B. McCusker and J. Perez-Pariente, Dalton Trans., 2011, 40, 8125, DOI: 10.1039/c1dt11045d. (b) A. Tuel, I. Arcon, N. Novak Tusar, A. Meden and V. Kaucic, Micro. Mater. 1996, 7, 271, DOI: 10.1016/S0927-6513(96)00076-4. 
Table 1. Typical gel compositions used for the synthesis of MAPO (M=Mg, Zn) STA-2.

\begin{tabular}{ccccccccc}
\hline & $\mathrm{Al}(\mathrm{OH})_{3}$ & $\mathrm{H}_{3} \mathrm{PO}_{4}$ & $\mathrm{Mg}(\mathrm{OAc})_{2}$ & $\mathrm{Zn}(\mathrm{OAc})_{2}$ & $\mathrm{R}(\mathrm{OH})_{2}{ }^{\mathrm{a}}$ & $\mathrm{H}_{2} \mathrm{O}$ & $\begin{array}{c}\mathrm{T} / \\
{ }^{\circ} \mathrm{C}\end{array}$ & $\begin{array}{c}\text { Duration/ } \\
\text { days }\end{array}$ \\
\hline $\mathrm{MgAPO}$ & $1.0-\mathrm{x}$ & 1.0 & $\mathrm{x}$ & - & 0.45 & 39.0 & 190 & 7 \\
$\mathrm{ZnAPO}$ & $1.0-\mathrm{x}$ & 1.0 & - & $\mathrm{x}$ & 0.45 & 39.0 & 190 & 7 \\
\hline
\end{tabular}

a $\mathrm{R}$ is the BQNB template

Table 2. MAPO materials studied in this work, with $\mathrm{Mg} / \mathrm{P}$ and $\mathrm{Zn} / \mathrm{P}$ ratios determined by EDX analysis.

\begin{tabular}{cc}
\hline Type & M/P ratios \\
\hline MgAPO & $0.03,0.04,0.06,0.07,0.16,017$ \\
ZnAPO & $0.05,0.07,0.08,0.09,0.11$ \\
\hline
\end{tabular}


Table 3. Experimental ${ }^{27} \mathrm{Al}$ NMR parameters obtained from MQMAS spectra (see Supplementary Information) of MAPO STA-2 materials. NMR parameters are only quoted for the partially resolved site where possible.

\begin{tabular}{|c|c|c|c|c|c|c|c|c|}
\hline \multirow{2}{*}{$\begin{array}{l}\mathrm{M} / \mathrm{P} \\
\text { ratio }\end{array}$} & \multicolumn{2}{|c|}{$\mathrm{Al}^{\mathrm{V}}$} & \multicolumn{6}{|c|}{$\mathrm{Al}^{\mathrm{IV}}$} \\
\hline & $\begin{array}{l}<\delta_{\text {iso }}> \\
(\mathrm{ppm}) \\
\end{array}$ & $\begin{array}{r}<\mathrm{P}_{\mathrm{Q}}>/ \\
\mathrm{MHz}\end{array}$ & $\begin{array}{l}<\delta_{\text {iso }}> \\
(\mathrm{ppm}) \\
\end{array}$ & $\begin{array}{c}<\mathrm{PQ}_{\mathrm{Q}}>/ \\
\mathrm{MHz}\end{array}$ & $\begin{array}{l}<\delta_{\text {iso }}> \\
(\mathrm{ppm}) \\
\end{array}$ & $\begin{array}{c}<\mathrm{P}_{\mathrm{Q}}>/ \\
\mathrm{MHz}\end{array}$ & $\begin{array}{l}<\delta_{\text {iso }}> \\
(\mathrm{ppm})\end{array}$ & $\begin{array}{r}<\mathrm{P}_{\mathrm{Q}}>/ \\
\mathrm{MHz}\end{array}$ \\
\hline \multicolumn{9}{|c|}{ AlPO STA-28,9 } \\
\hline 08,9 & $17.1(10)$ & $2.4(4)$ & $39.1(10)$ & $2.0(4)$ & $45.0(10)$ & $2.9(4)$ & $49.0(2)$ & $2.6(4)$ \\
\hline \multicolumn{9}{|c|}{ MgAPO STA-2 } \\
\hline 0.03 & $16.8(10)$ & $2.8(3)$ & $38.9(10)$ & $2.1(4)$ & & & $46.8(10)$ & $3.0(4)$ \\
\hline 0.04 & $16.7(10)$ & $2.9(3)$ & $38.9(10)$ & $2.2(4)$ & & & $45.3(10)$ & $3.3(4)$ \\
\hline 0.06 & $16.6(10)$ & $2.8(3)$ & $38.8(10)$ & $2.2(4)$ & & & $46.0(10)$ & $3.1(4)$ \\
\hline 0.07 & $16.4(10)$ & $2.8(3)$ & $38.7(10)$ & $2.1(4)$ & & & $45.3(13)$ & $3.0(4)$ \\
\hline 0.16 & $15.6(17)$ & $2.9(3)$ & $38.4(10)$ & $2.3(4)$ & & & $44.2(12)$ & $3.2(4)$ \\
\hline 0.17 & $15.3(17)$ & $2.6(5)$ & $38.4(10)$ & $2.5(4)$ & & & $43.0(10)$ & $3.2(4)$ \\
\hline \multicolumn{9}{|c|}{ ZnAPO STA-2 } \\
\hline 0.05 & $17.0(10)$ & $2.5(4)$ & 38.7 (13) & $2.0(3)$ & & & $46.8(10)$ & $3.0(3)$ \\
\hline 0.07 & $17.1(10)$ & $2.8(3)$ & $39.0(10)$ & $2.0(3)$ & & & $46.7(10)$ & $3.0(3)$ \\
\hline 0.08 & $17.1(13)$ & $3.0(3)$ & $38.9(10)$ & $2.2(3)$ & $42.8(13)$ & $2.9(3)$ & $45.3(13)$ & $2.9(3)$ \\
\hline 0.09 & $16.6(10)$ & $2.8(3)$ & $38.8(10)$ & $2.1(3)$ & & & $45.8(10)$ & $3.0(3)$ \\
\hline 0.11 & $16.4(10)$ & $3.0(3)$ & $38.5(13)$ & $2.2(5)$ & & & $44.8(10)$ & $3.0(3)$ \\
\hline
\end{tabular}


Table 4. Ratio of the (integrated) intensities of ${ }^{27} \mathrm{Al}$ resonances corresponding to four- and five-coordinate $\mathrm{Al}$ species, $\mathrm{Al}{ }^{\mathrm{IV}} / \mathrm{Al}^{\mathrm{V}}$, extracted from the MAS spectra (14.1 T) of MgAPO STA-2 materials.

\begin{tabular}{cc}
\hline $\mathrm{Mg} /$ P ratio & $\mathrm{Al}^{\mathrm{IV}} / \mathrm{Al}^{\mathrm{V}}$ ratio \\
\hline 08,9 & $1.7(5)$ \\
0.03 & $1.4(5)$ \\
0.04 & $2.1(5)$ \\
0.06 & $3.3(5)$ \\
0.07 & $5.8(10)$ \\
0.16 & $15.6(20)$ \\
0.17 & $18.2(20)$ \\
\hline
\end{tabular}

Table 5. Ratio of the (integrated) intensities of ${ }^{27} \mathrm{Al}$ resonances corresponding to $\mathrm{Al}{ }^{\mathrm{IV}}$ species derived from Al1 (Al11-Al16) and Al2 (A121-26), extracted from the MQMAS spectra (see Supplementary Information) of MAPO STA-2 materials.

\begin{tabular}{cccc}
\hline M/P ratio & Al1/ Al2 ratio & M/P ratio & Al1/ A12 ratio \\
\hline MgAPO STA-2 & & ZnAPO STA-2 & \\
0.03 & $0.95(3)$ & 0.05 & $0.8015)$ \\
0.04 & $0.70(10)$ & 0.07 & $0.89(15)$ \\
0.06 & $0.86(3)$ & 0.08 & - \\
0.07 & $0.88(4)$ & 0.09 & $0.98(10)$ \\
0.16 & $0.58(4)$ & 0.11 & $0.84(10)$ \\
0.17 & $0.40(10)$ & & \\
\hline
\end{tabular}




\section{Figure captions}

Figure 1. (a) Framework structure of STA-2, with Al1, Al2, P1 and P2 shown by green, red, yellow and blue spheres, respectively, showing the secondary building units (SBUs), (b) part of the structure of as-made STA-2, showing the template (BQNB) within the pores and (c) unit cell used for DFT calculations of as-made Mg substituted STA-2.

Figure 2. (a) ${ }^{27} \mathrm{Al}(14.1 \mathrm{~T}, 12-14 \mathrm{kHz} \mathrm{MAS})$, (b) ${ }^{31} \mathrm{P}(14.1 \mathrm{~T}, 12-14 \mathrm{kHz} \mathrm{MAS})$ and (c) ${ }^{1} \mathrm{H}(9.4$ T, $40 \mathrm{kHz}$ MAS) MAS NMR spectra of MgAPO STA-2, with compositions (as determined by EDX) shown. Spectra of the pure AlPO form (made in this case with the BDAB template) are shown for comparison.

Figure 3. Isotropic projections of ${ }^{27} \mathrm{Al}(14.1 \mathrm{~T}, 12-14 \mathrm{kHz}$ MAS) MQMAS NMR spectra of MgAPO STA-2 samples with $\mathrm{Mg} / \mathrm{P}$ ratios (as determined by EDX) of 0.03 and 0.17 , demonstrating the decrease in intensity of the resonance at lower chemical shift, attributed to Al11-16 in S6R. Full two-dimensional spectra are shown in the Supplementary Information.

Figure 4. Calculated (using CASTEP) ${ }^{27} \mathrm{Al}$ (left) and ${ }^{31} \mathrm{P}$ (right) isotropic chemical shifts for a range of models of MgAPO STA-2 (using the reduced unit cell shown in Figure 1c, of formula $\mathrm{Al}_{10} \mathrm{Mg}_{2} \mathrm{P}_{12} \mathrm{O}_{48}(\mathrm{BQNB})$, i.e., a $\mathrm{Mg} / \mathrm{P}$ ratio of 0.167$)$, with substitution of (c, d) $2 \mathrm{Mg}$ for $2 \mathrm{Al} 1(\mathrm{e}, \mathrm{f}) 2 \mathrm{Mg}$ for $2 \mathrm{Al} 2$ and $(\mathrm{g}, \mathrm{h}) 2 \mathrm{Mg}$ for $1 \mathrm{Al} 1$ and $1 \mathrm{Al} 2$. Also included for comparison are the experimental spectra (and isotropic ${ }^{27} \mathrm{Al}$ chemical shifts - marked as crosses) for MgAPO STA-2 (Mg/P = 0.17).

Figure 5. Plot comparing the calculated $31 \mathrm{P}$ isotropic chemical shifts (for models of MgAPO STA-2 with Mg/P = 0.1667), and the average P-O-M (where $\mathrm{M}$ is $\mathrm{Al}$ or $\mathrm{Mg}$ ), bond angles. Sites resulting from "P1" (i.e., P11-16) and "P2" (i.e., P21-26) are shown in yellow and blue, respectively. Also indicated is the number of $\mathrm{Mg} \mathrm{NNN}$ species. 
Figure 6. (a) ${ }^{27} \mathrm{Al}$ (14.1 T, 12-14 kHz MAS), (b) ${ }^{31} \mathrm{P}\left(14.1 \mathrm{~T}, 12-14 \mathrm{kHz}\right.$ MAS) and (c) ${ }^{1} \mathrm{H}(9.4$ T, $40 \mathrm{kHz}$ MAS) MAS NMR spectra of ZnAPO STA-2, with compositions (as determined by EDX) shown. 
Figure 1

(a)

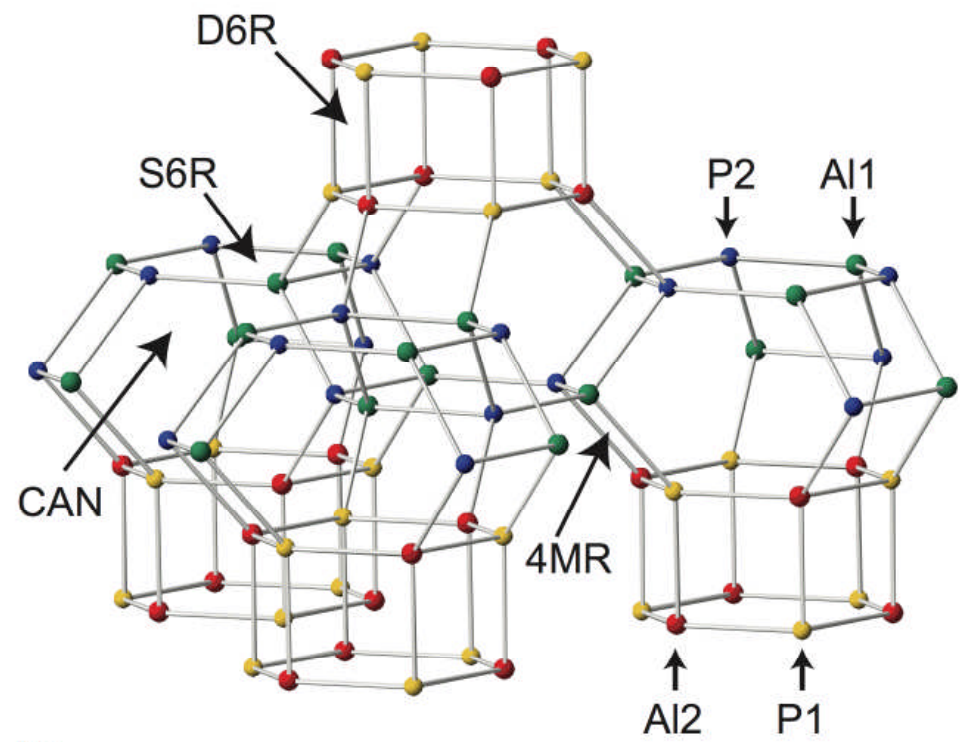

(b)

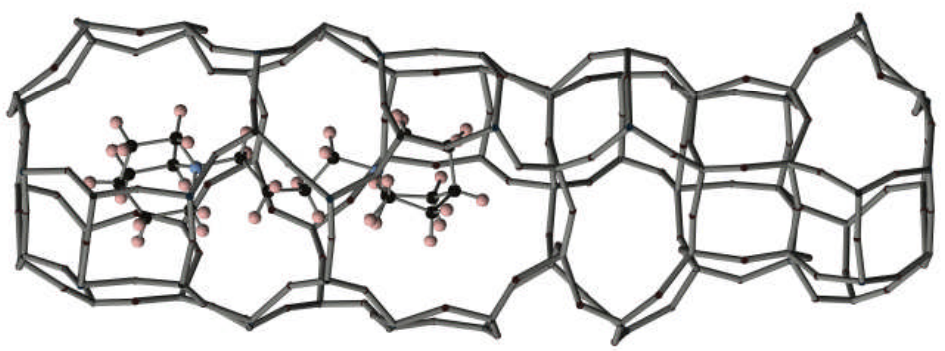

(c)

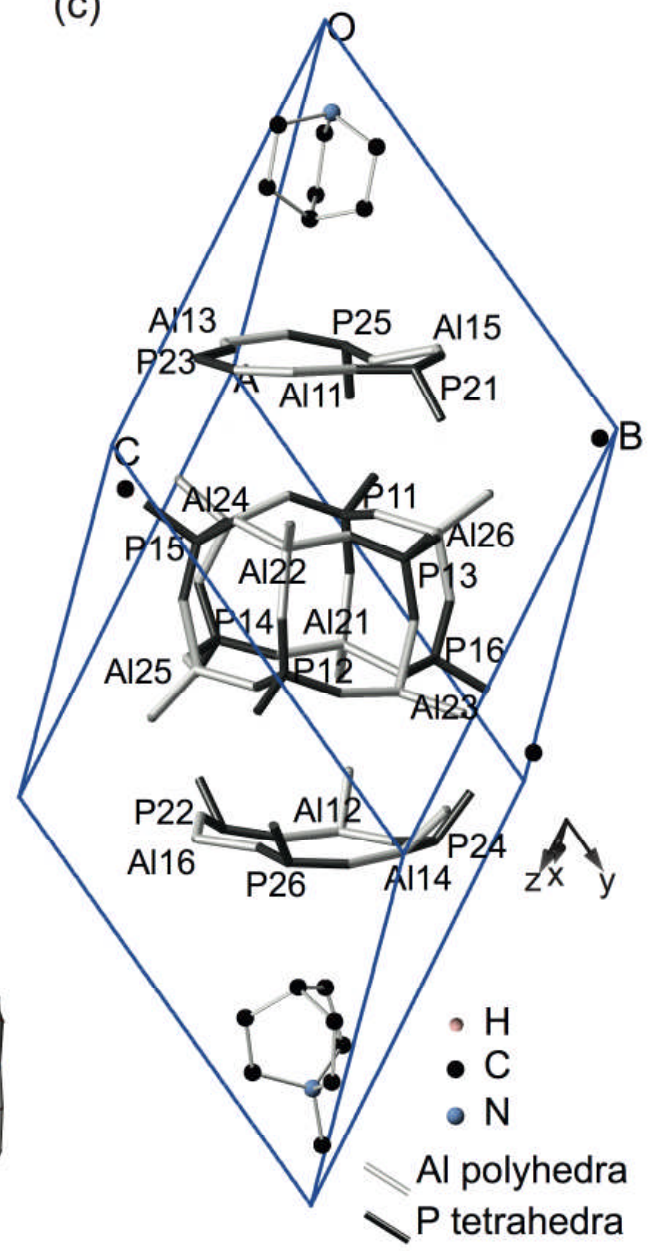


Figure 2

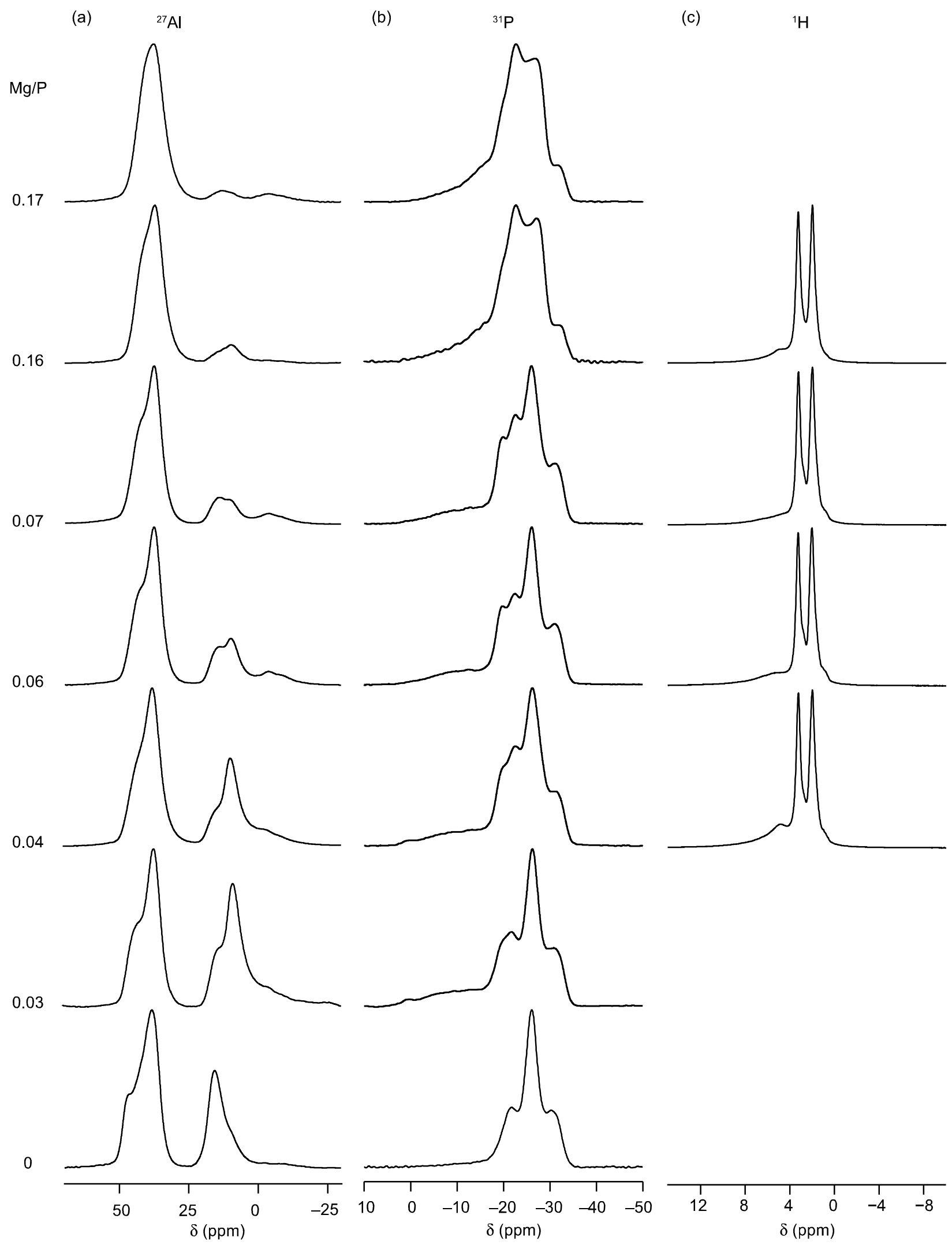

31 
Figure 3

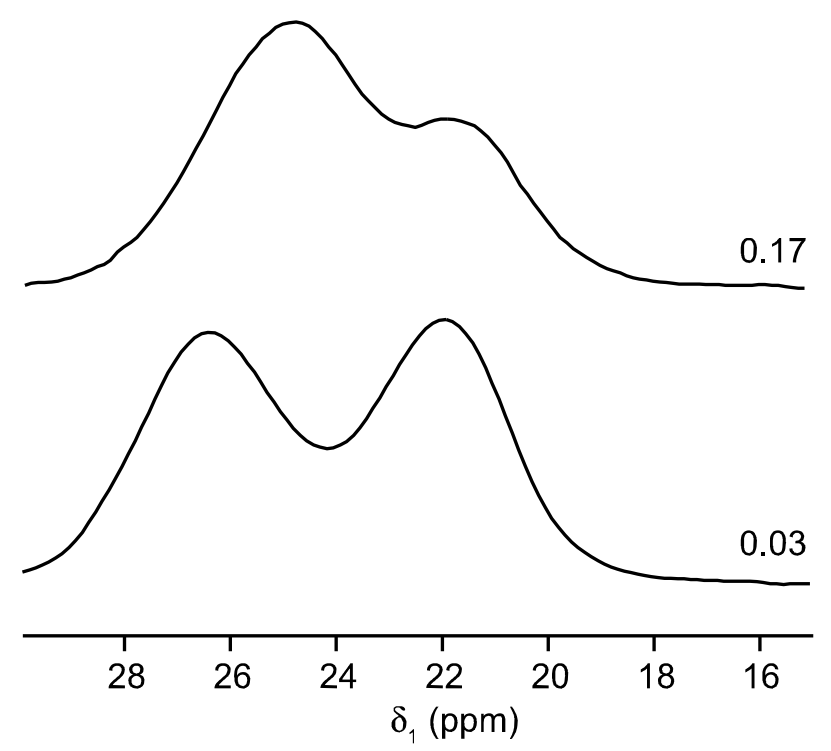




\section{Figure 4}
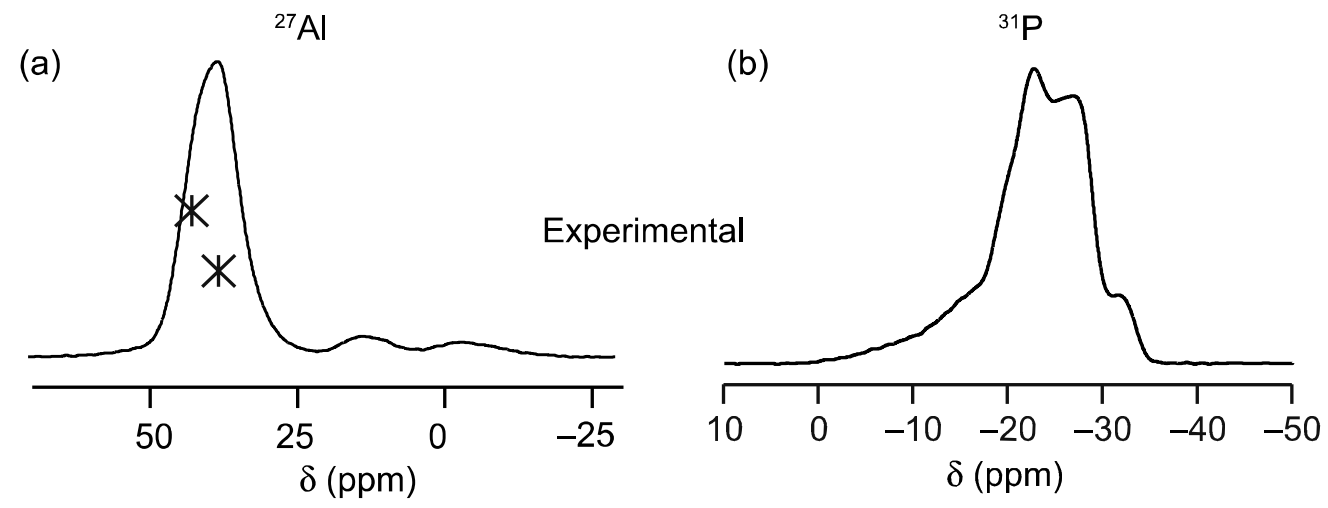

(c)

(d)

D6R

$$
2 \mathrm{Mg} \rightarrow 2 \mathrm{Al} 1
$$

S6R

\section{$4 \mathrm{Al}$}

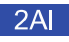

3AI S6R

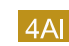

3Al D6R

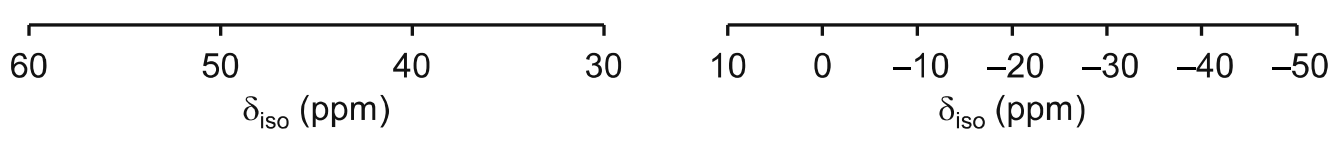

(e)

(f)

D6R

$$
2 \mathrm{Mg} \rightarrow 2 \mathrm{Al} 2
$$

S6R

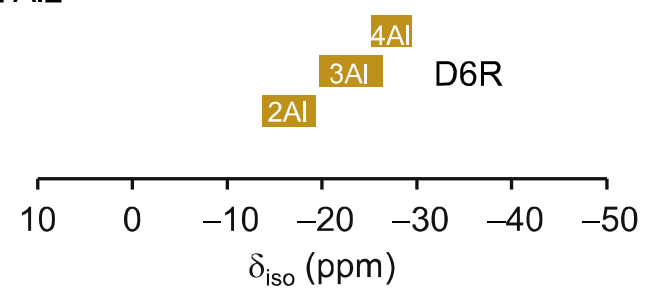

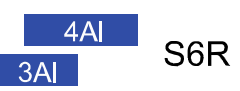

$4 \mathrm{~A}$

3Al D6R (g)

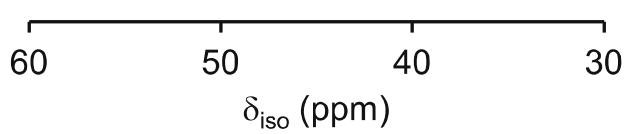
$2 \mathrm{Mg} \rightarrow 1 \mathrm{Al} 1 \& 1 \mathrm{Al} 2$

D6R

S6R

$\begin{array}{lll}60 \quad 50 \quad 40 & 30 \\ & \delta_{\text {iso }}(\mathrm{ppm}) & \end{array}$

(h)

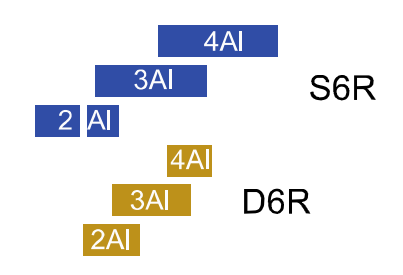

$\begin{array}{ccccccc}10 & 0 & -10 & -20 & -30 & -40 & -50 \\ & \delta_{\text {iso }}(\mathrm{ppm}) & & & \end{array}$ 


\section{Figure 5}

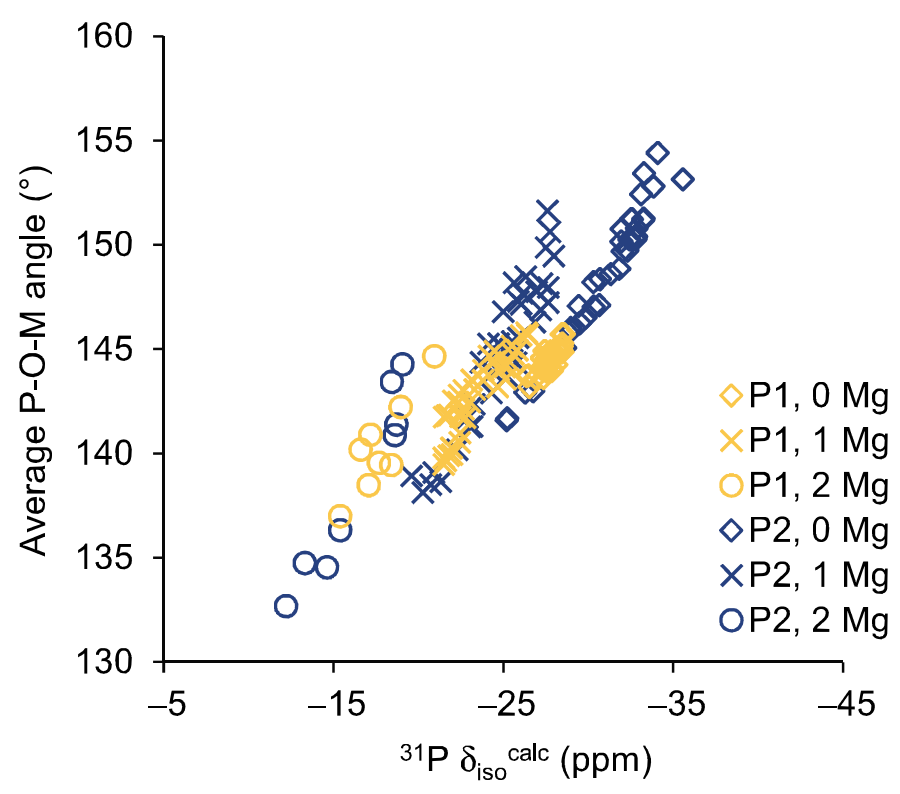


Figure 6

(a)

${ }^{27} \mathrm{Al}$
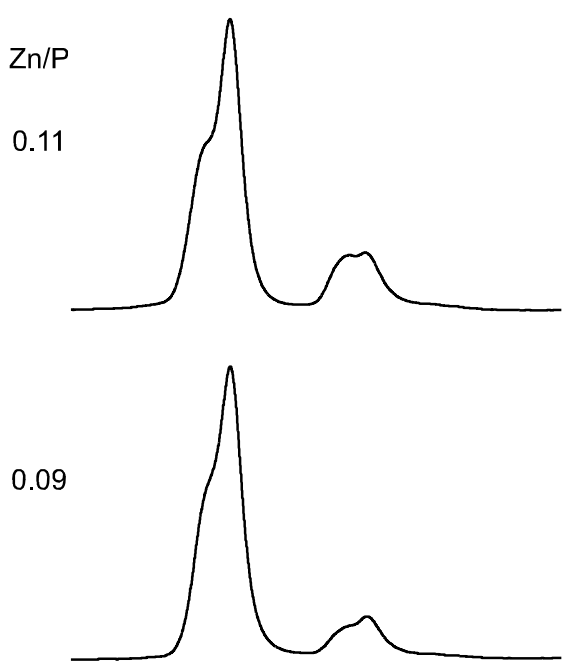

0.08

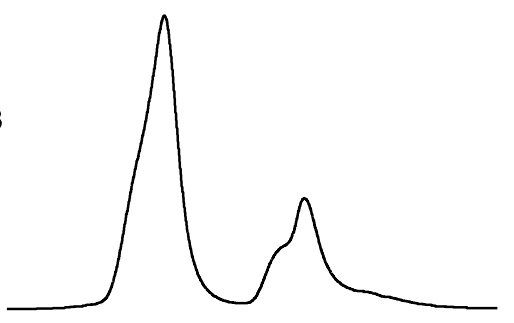

0.0

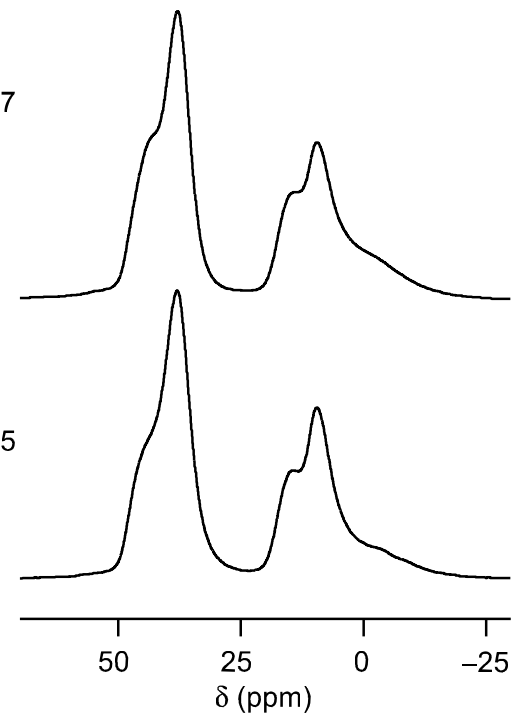

(b)

${ }^{31} \mathrm{P}$

(c)

${ }^{1} \mathrm{H}$
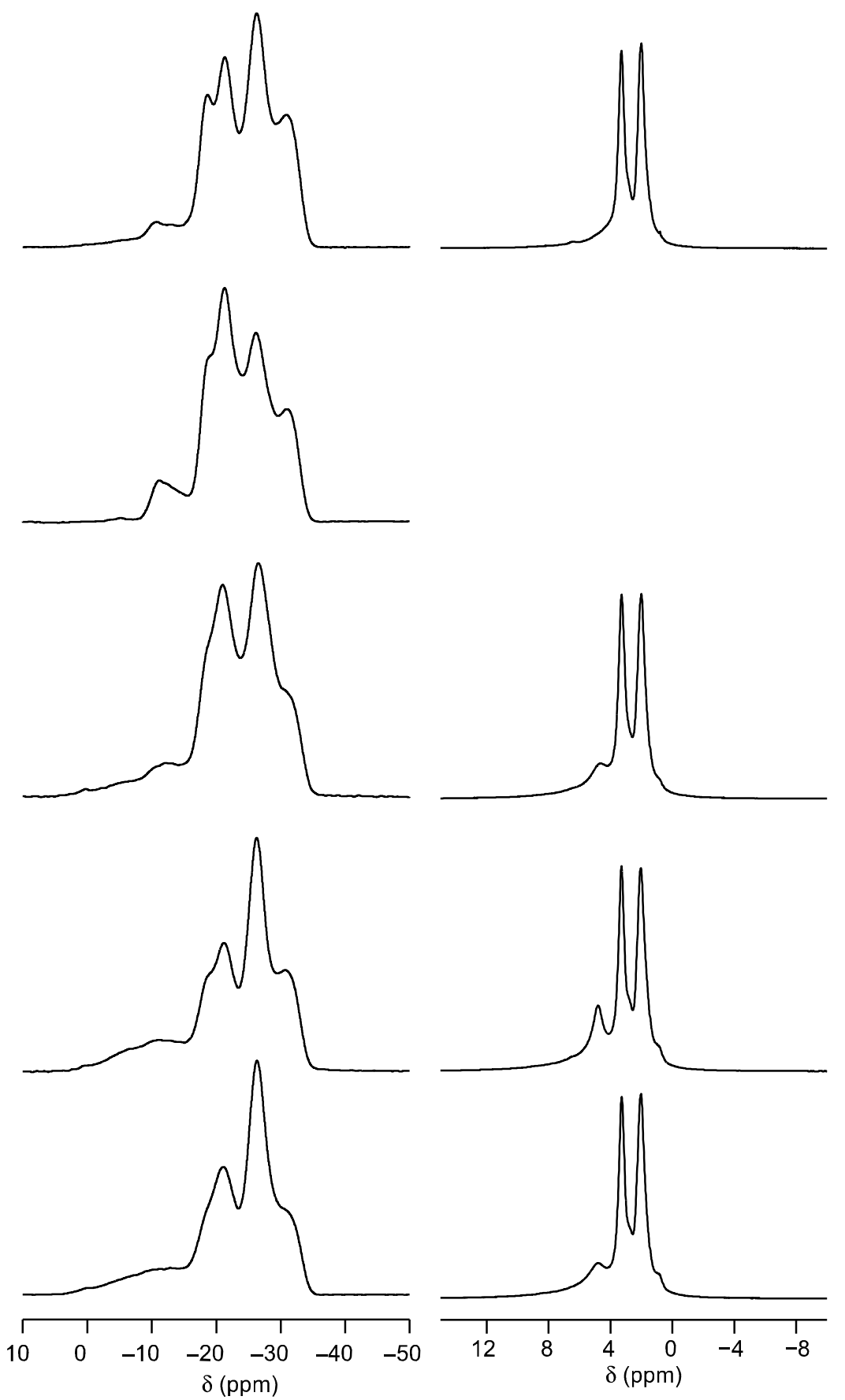
TOC graphic

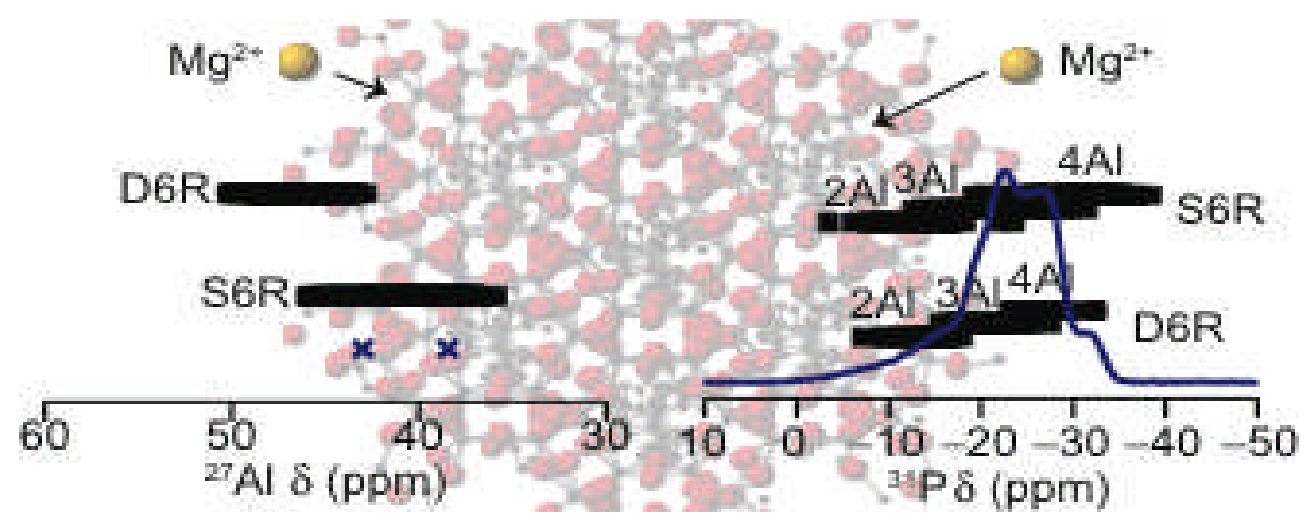

\section{Highlights}

Investigation of cation substitution into the framework of the AlPO STA-2.

Combined NMR crystallography approach, using diffraction, NMR and DFT calculations.

NMR chemical shift sensitive to local geometry and next-nearest coordinating atoms. 